\title{
Structural Properties of 4-Substituted Phenols Capable of Proton-Coupled Electron Transfer to Superoxide
}

\author{
Tatsushi Nakayama, Bunji Uno* \\ Gifu Pharmaceutical University, Daigaku-nishi, Gifu , Japan \\ uno@gifu-pu.ac.jp
}

\begin{abstract}
The structural properties of 4-substituted phenols capable of proton-coupled electron transfer (PCET) to superoxide $\left(\mathrm{O}_{2}{ }^{--}\right)$were investigated on the basis of electrochemical and electron spin resonance (ESR) spectral measurements and supported by density functional theory calculations. Although the proton and electron donating abilities of phenols are considered to be important factors in PCET reactions, the major mechanism for the reactions between 4-substitued monophenols and $\mathrm{O}_{2}{ }^{--}$is the proton-transfer pathway that is independent of the electronic substituent effect. Conversely, the presence of 4-aminophenol in addition to p-hydroquinone distinctly affects the reversible $\mathrm{O}_{2} / \mathrm{O}_{2}{ }^{\cdot-}$ redox pair; the associated PCET reaction occurs from the 4-aminophenol to $\mathrm{O}_{2}{ }^{\cdot-}$ to give a stable intermediate radical in the redox system. The generation of p-benzoquinone imine radical was inferred from the results obtained from ESR spectral measurements. B3LYP/PCM/6-31+G(d,p) calculations indicate that the $\mathrm{O}_{2}{ }^{{ }^{-}-}$-scavenging reaction involves a primary proton transfer from 4-aminophenol to $\mathrm{O}_{2}{ }^{--}$to give $\mathrm{HO}_{2}{ }^{-}$, followed by a one-step concerted PCET reaction to yield p-benzoquinone imine radical and $\mathrm{H}_{2} \mathrm{O}_{2}$. The structural properties of 4-aminophenol are important in the $\mathrm{O}_{2}{ }^{--}$-scavenging PCET reaction; 4-aninophenol is characterized by a $\pi$ electronic redox system involving two protons and two electrons, similar to the quinone-hydroquinone redox system.
\end{abstract}

Keywords: proton-coupled electron transfer, 4-substituted phenols, superoxide, hydroperoxy radical

\section{INTRODUCTION}

The beneficial properties of phenolic compounds are primarily related to their antioxidant activities, which are associated with their protective role in interrupting chain reactions, such as lipid peroxidation $[1,2]$. These activities have been attributed to proton-coupled electron transfer (PCET). Therefore, free radical scavenging by phenolic compounds has been widely studied experimentally and theoretically from kinetic and thermodynamic perspectives [4-27]. However, the free radical scavenging mechanism of phenolic antioxidants is still controversial; for example, a concerted pathway of sequential PCET, $\mathrm{H}$-atom transfer (HAT) involving concerted PCET, and sequential proton loss electron transfer (SPLET) to intermediate radicals $[21,22]$ have all been proposed.

As a free radical, $\mathrm{O}_{2}{ }^{-}$is an important biological intermediate in living cells [28] and is overproduced in tissues that are subject to chronic infection and inflammation [29]. $\mathrm{O}_{2}{ }^{-}$causes oxidative DNA damage in living tissues under inflammatory conditions [30-33]. The reactivity of $\mathrm{O}_{2}{ }^{-}$against substituted monophenols (POHs) has been electrochemically studied in aprotic solvents such as dimethylformamide (DMF) and dimethyl sulfoxide [34-38]. It has been proposed that the major mechanism for the reaction is the proton-transfer pathway involving only one $\mathrm{OH}$ between the electrogenerated $\mathrm{O}_{2}{ }^{--}$, acting as a weak base, and $\mathrm{POH}$, acting as an acid. Recently, a few studies have suggested an electron-transfer pathway involving HAT and including concerted PCET [23-26] and SPLET $[21,22]$ rather than a proton-transfer pathway for the reaction between electrogenerated $\mathrm{O}_{2}{ }^{--}$and phenolic flavonoids. However, these studies provide insufficient information about the structural and electronic properties of the POHs involved in PCET to $\mathrm{O}_{2}{ }^{\circ-}$. As expected, the reactivity depends on the chemical nature of the substituents present on the $\mathrm{POH}$. For example, changes in acid dissociation and the electron donating or accepting abilities of the substituents are among the most important parameters 
that influence the PCET reaction. In this vein, numerous investigations have been devoted to the chemical and physicochemical properties of phenolic compounds (especially flavonoids) [1-33]. Studies have been reported on the determination of the oxidation potentials, $\mathrm{p} K_{\mathrm{a}}$ values, and spectral properties of these compounds. However, controversies still exist regarding the meaning of these data. Moreover, it is reasonable to assume a PCET model comprising $\mathrm{O}_{2}{ }^{-}$and two $\mathrm{POH}$ molecules for the $\mathrm{O}_{2}{ }^{-}$-scavenging reaction involving two protons and one electron, as shown in Fig. 1 [26,39]. In this context, we recently presented some preliminary results showing that the PCET reaction of $\mathrm{O}_{2}{ }^{-}$occurs only with hydroquinone and catechol, which have two hydroxyl groups per molecule [25]. In this work, we have explored and developed this possibility to gain more insight into the mechanism involved in the reaction of electrogenerated $\mathrm{O}_{2}{ }^{--}$with 4-substitued POHs. We show that the $\mathrm{O}_{2}{ }^{-{ }^{-}}$-scavenging reaction of 4-aminophenol proceeds efficiently by a one-step concerted PCET mechanism after primary proton transfer. This is attributed to the stability of the intermediate radical in the $\mathrm{POH}$ redox system rather than the electronic substituent effect of the $\mathrm{POH}$.

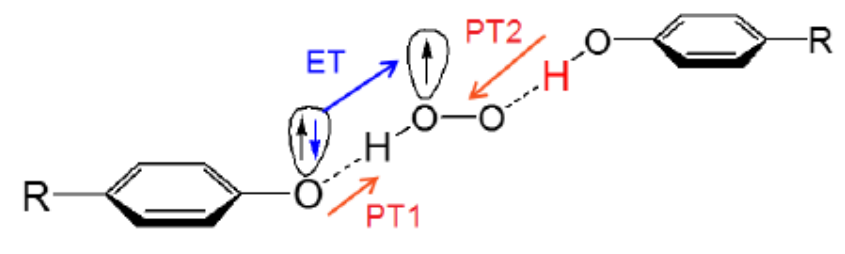

Fig.1. Model of the PCET reaction for $\mathrm{O}_{2}{ }^{-{ }^{-}}$-scavenging by 4-substituted POHs. The abbreviations ET and PT denote electron transfer and proton transfer, respectively.

\section{EXPERIMENTAL}

\subsection{Chemicals}

4-Substituted POHs used in this study were 4-cyanophenol, 4-bromophenol, phenol, 4-tert-butylphenol, 4-methoxyphenol, 4-aminophenol, and 4-dimethylaminophenol. 4-Cyanophenol, 4-bromophenol, and 4-methoxyphenol are commercially available from Tokyo Chemical Industry Co., Ltd. and used as received without further purification. 4-tert-Butylphenol and 4-aminophenol were purchased from Tokyo Chemical Industry Co., Ltd. and were purified by sublimation under reduced pressure just before use. Phenol and 4-methoxyphenol were purchased from Wako Pure Chemical Industries, Ltd. and Tokyo Chemical Industry Co., Ltd., respectively, and used as received without further purification. 4-Dimethylaminophenol was synthesized according to the literature [40]. The solvent for electrochemical and ESR spectral measurements was spectrograde purity DMF available from Sigma-Aldrich Co. LLC. and used as received. Tetrapropylammonium perchlorate (TPAP) was prepared as described previously [41] and used as a supporting electrolyte for DMF. Ferrocene ( $\mathrm{Fc})$, used as a potential reference compounds, was commercially available from Nacalai Tesque Inc. and purified by repeated sublimation under reduced pressure immediately prior to use.

\subsection{Electrochemical and Spectroelectrochemical Measurements}

Cyclic voltammetry was performed with a three-electrode system comprising a glassy carbon (GC) working electrode, a coiled platinum counter electrode, and an $\mathrm{Ag} / \mathrm{AgNO}_{3}$ reference electrode (containing $\mathrm{CH}_{3} \mathrm{CN}$ solution of $0.1 \mathrm{~mol} \mathrm{dm}^{-3} \mathrm{TBAP}$ and $0.01 \mathrm{~mol} \mathrm{dm}^{-3} \mathrm{AgNO}_{3}$; BAS RE-5) at $25^{\circ} \mathrm{C}$ using a BAS 100B electrochemical workstation, coupled to a Dell Optiplex760 PC using BAS electrochemical software to record and analyze the data.

In situ electrochemical ESR spectra were observed using a JEOL JES-FA200 X-band spectrometer. The controlled potential electrolysis was performed at room temperature in an electrochemical ESR cell using a 0.5 - $\mathrm{mm}$-diameter straight $\mathrm{Pt}$ wire sealed in a glass capillary as a working electrode [42].

Samples were prepared in a glove box completely filled with $\mathrm{N}_{2}$ gas to prevent contamination by moisture. The DMF solution containing $0.1 \mathrm{~mol} \mathrm{dm}^{-3}$ TPAP as a supporting electrolyte was saturated 
with $\mathrm{O}_{2}$ by bubbling the gas for ca. 2-3 min and the gas was passed over the solutions during the electrochemical and ESR measurements to maintain the concentration of $\mathrm{O}_{2}$ at a constant level. The equilibrium concentration of $\mathrm{O}_{2}$ was calculated as $4.8 \times 10^{-3} \mathrm{~mol} \mathrm{dm}^{-3}$.

\subsection{Theoretical Calculations}

All solution-phase calculations were performed using Gaussian 09 Program package [43]. Geometry of each compound and radical or ionic structure was optimized using DFT method with B3LYP functional using 6-31+G(d,p) basis sets. Solvent contribution of DMF to the standard Gibbs formation energies was computed employing integral equation formalism polarized continuum model (IEF-PCM) method that is widely employed in the description of the thermodynamic characteristics of solvation. The PCM calculations were performed using default settings of Gaussian 09 Program package. The zero-point energies and thermal correction, together with the entropies, were used to convert the internal energies to standard Gibbs energy at $298.15 \mathrm{~K}$.

\section{RESULTS AND DISCUSSION}

\subsection{Cyclic Voltammetry of $\mathrm{O}_{2}$ in the Presence of 4-Substituted POHs}

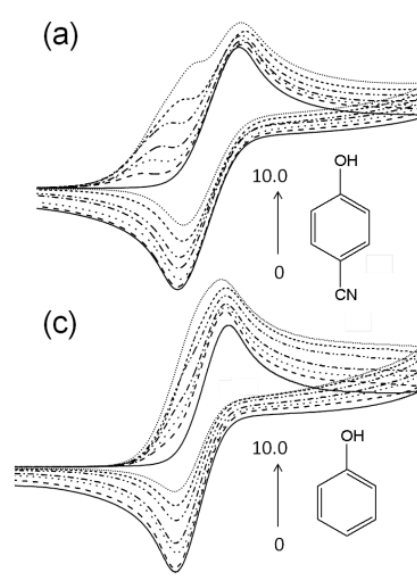

(b)

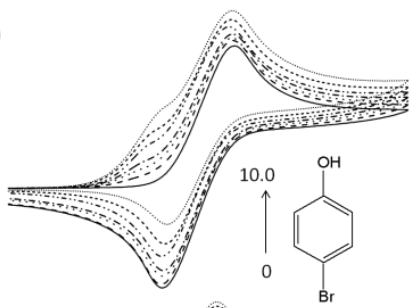

(e)

(d)
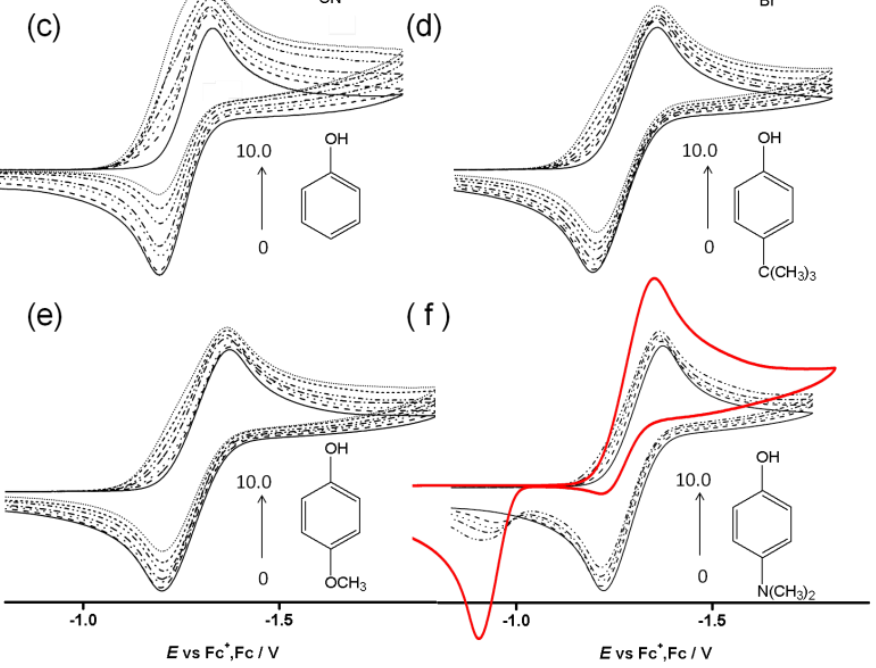

Fig.2. Cyclic voltammograms of $\mathrm{O}_{2}$ in the absence and presence of 4-substitued POHs in DMF containing $0.1 \mathrm{~mol} \mathrm{dm} \mathrm{m}^{-3}$ TPAP on a GC electrode at a scan rate of $0.1 \mathrm{~V} \mathrm{~s}^{-1}$. The concentrations of the

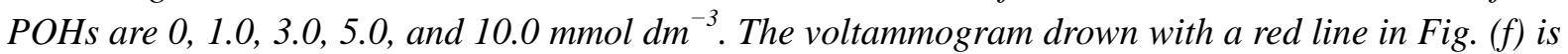
observed in the presence of $50 \mathrm{mmol} \mathrm{mm}^{-3}$ 4-dimethylaminophenol.

$\mathrm{O}_{2}$ exhibits a reversible redox wave that corresponds to the generation of $\mathrm{O}_{2}{ }^{--}$, as shown in Fig. 2. Our estimations of the reactivity between $\mathrm{O}_{2}{ }^{--}$and 4-substituted POHs are based on modifications of a cyclic voltammogram of the $\mathrm{O}_{2} / \mathrm{O}_{2}{ }^{--}$redox pair when the $\mathrm{POH}$ is added. The $\mathrm{p} K_{\mathrm{a}}$ values and HOMO energies of 4-substituted POHs are listed in Table 1. As expected, the apparent effect on the $\mathrm{O}_{2} / \mathrm{O}_{2}{ }^{-}$ electrochemistry depends on the chemical nature of the substituents present on the POHs, as shown in Fig.2. Clearly, upon the addition of $\mathrm{POH}$, the anodic peak current for reoxidation of $\mathrm{O}_{2}{ }^{--}$tends to decrease with increasing $\mathrm{POH}$ acidity. This behavior is attributed to the elimination of $\mathrm{O}_{2}{ }^{--}$by initial proton transfer from a $\mathrm{POH}$ to give $\mathrm{HO}_{2}{ }^{\circ}$ [34-38]. Depending on the acidity of the $\mathrm{POH}$, this decrease could be concomitant with an increase of the cathodic peak current (Fig. 2c-f) or with the appearance of a prepeak (Fig. 2a-b). The reduction prepeak that appears upon the addition of 4-cyanophenol and 4-bromophenol is interpreted as the reduction wave of $\mathrm{HO}_{2}{ }^{\circ}$. A fast protonation by the phenol to 
produce electrically neutral $\mathrm{HO}_{2}{ }^{-}$from $\mathrm{O}_{2}{ }^{--}$precedes the second electron transfer reaction, causing a potential inversion that corresponds to the case when the addition of the second electron is thermodynamically more favorable than the addition of the first one. Consequently, $\mathrm{O}_{2}{ }^{-}$formation after the primary electrode process associated with proton transfer from the phenol leads to the irreversible overall reduction of $\mathrm{O}_{2}$ to $\mathrm{H}_{2} \mathrm{O}_{2}$, driven by the exergonic reduction of the resulting $\mathrm{HO}_{2}{ }_{2}$. Conversely, the presence of weakly acidic POHs, such as 4-methoxyphenol and 4-dimethylaminophenol, does not result in the appearance of a well-defined prepeak because $\mathrm{O}_{2}{ }^{-}$is a weak base and its protonation by a weak acid is quite thermodynamically unfavorable. However, the two-electron reduction is facilitated by the subsequent homogeneous disproportionation reaction that displaces the proton transfer equilibrium [34-38]. In this situation, regardless of the acidity, as the $\mathrm{POH}$ concentration increases, the $\mathrm{O}_{2}$ reduction changes from a monoelectronic reversible wave to an irreversible two-electron reduction wave. Indeed, the presence of the 4-dimethylaminophenol, which is the most weakly acidic $\mathrm{POH}$, induces an apparent irreversible two-electron reduction to $\mathrm{H}_{2} \mathrm{O}_{2}$ at high concentrations (red line in Fig. 2f). The anodic peak that appears at approximately $-0.7 \mathrm{~V}$ in the reverse scan can be ascribed to the oxidation of the generated phenolate anion. The results indicate that the major mechanism for the reactions between $\mathrm{O}_{2}{ }^{-}$ and 4-substituted POHs is the proton-transfer pathway, irrespective of the phenolic acidity and HOMO energy (ionization potential). These behaviors are consistent with previously documented results [34-38].

\subsection{Cyclic Voltammetric and ESR Spectral Measurements of $\mathrm{O}_{2}$ in the Presence of 4-Aminophenol}

Unlike other POHs, the presence of 4-aminophenol is only associated with an apparent decrease in the reversibility of the $\mathrm{O}_{2} / \mathrm{O}_{2}{ }^{-}$redox pair, as shown in Fig. 3. A monoelectronic process with the disappearance of the reoxidation wave indicates that the $\mathrm{HO}_{2}{ }^{\circ}$ produced in the electrochemical process in the presence of 4-aminophenol is consumed immediately in the reaction with the $\mathrm{POH}$ or $\mathrm{PO}^{-}$, without being heterogeneously reduced on the electrode. The results shown in Fig. 3 are the same as those obtained previously for hydroquinone (4-hydroxyphenol) and catechol (2-hydroxyphenol) $[25,26]$. This indicates that 4-aminophenol is involved in the PCET reaction of $\mathrm{O}_{2}{ }^{-{ }^{-}}$scavenging. The electron transfer from 4-aminophenol or 4-aminophenolate anion to $\mathrm{HO}_{2}{ }^{\circ}$ has been inferred from ESR spectral measurements. Figure 3 also presents the ESR spectrum of the $\mathrm{O}_{2}$ solution containing 4-aminophenol obtained by controlled-potential electrolysis at an applied potential of $-1.3 \mathrm{~V}$, corresponding to the reduction of $\mathrm{O}_{2}$. A well-defined hyperfine structure was observed for the ESR spectrum, with excellent repeatability. However, the radical structure was not precisely identified. We infer the structure to be $p$-benzoquinone radical anion $\left(a_{\mathrm{H}}=0.26 \mathrm{mT}\right)$, derived from the radical anion of $p$-benzoquinone imine by hydrolysis [44]. The 4-aminophenol redox reaction involving $p$-benzoquinone imine is expected to act as a quinone-hydroquinone $\pi$-conjugated redox system characterized by PCET via the stable intermediate radical anion.

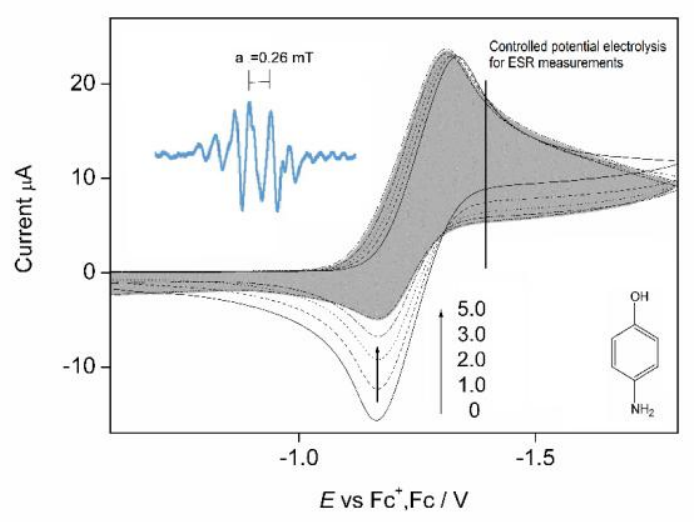

Fig.3. Cyclic voltammograms of $\mathrm{O}_{2}$ in the absence and presence of 4-aminophenol in DMF containing $0.1 \mathrm{~mol}$ $d m^{-3} T P A P$ on a GC electrode at a scan rate of $0.1 \mathrm{~V} \mathrm{~s}^{-1}$, and the ESR spectrum obtained by controlled-potential electrolysis of $\mathrm{O}_{2}$ solution $(D M F)$ containing 4-aminophenol $\left(5.0 \mathrm{mmol} \mathrm{dm^{-3 }}\right)$ at an applied potential of $-1.3 \mathrm{Vvs}$ $\mathrm{Fc}^{+} / \mathrm{Fc}$. The concentrations of 4-aminophenol are $0,1,2,3$, and $5 \mathrm{mmol} \mathrm{dm}{ }^{-3}$. 


\subsection{Energetics for the Reaction of $\mathrm{O}_{2}{ }^{--}$with 4-Substituted POHs}

Figure 4 shows six diabatic electronic states for a PCET reaction involving the transfer of one electron and two protons based on the model shown in Fig. 1. Table 1 lists the standard Gibbs energy changes $\left(\Delta G^{\circ}\right)$ of the six diabatic electronic states shown in Fig. 4 for the 4-substituted POHs investigated here. A proposed low energy pathway based on this model is sequential PCET, involving electron transfer between $\mathrm{PO}^{-}$and $\mathrm{HO}_{2}{ }^{\circ}$ (ET2), followed by proton transfer from the other $\mathrm{POH}$ to the resulting $\mathrm{HO}_{2}{ }^{-}$ (PT4) after the initial proton transfer (PT1) from $\mathrm{POH}$ to $\mathrm{O}_{2}{ }^{-}$. However, the protonation of $\mathrm{O}_{2}{ }^{--}$by phenolic compounds is generally thermodynamically unfavorable because $\mathrm{O}_{2}{ }^{-}$is a weak base. In fact, the $\Delta G^{\circ}$ values for the initial proton transfer (PT1) are always positive for calculations that include solvent effects, as shown in Table 1. In addition, the substituent effect on PT1 conflicts with that on ET2. For example, the electron-withdrawing nature of the $\mathrm{CN}$ substituent makes the protonation of $\mathrm{O}_{2}{ }^{-}$ feasible but weakens the electron-donating ability of the POH. Therefore, all the substituted POHs investigated here are thermodynamically unfavorable for the model, as listed in Table 1 . We note here that the favorable electron-transfer reaction (ET3 process), contributed by electron-donating substituents such as the $\mathrm{N}\left(\mathrm{CH}_{3}\right)_{2}$ group, is prevented by the kinetics of the disproportionation reaction of $\mathrm{HO}_{2}$. The calculation results provide a good explanation for the fact that the major mechanism of the reaction between $\mathrm{O}_{2}{ }^{-}$and 4-substituted $\mathrm{POHs}$ (except for 4-aminophenol) is a proton-transfer pathway facilitated by a subsequent homogeneous disproportionation reaction that displaces the proton transfer equilibrium.

Table1. $p K_{a}$ values and HOMO energies of 4-substituted POHs and $\triangle G^{\circ}$ values for the PCET reaction (Fig. 1) between $\mathrm{O}_{2}{ }^{--}$and 4-substitued POHs, calculated using the B3LYP/6-31+G(d,p) method.

\begin{tabular}{|c|c|c|c|c|c|c|c|c|c|c|}
\hline \multirow{2}{*}{ Substituents } & \multirow{2}{*}{$\mathrm{p} K_{\mathrm{a}}$} & \multirow{2}{*}{$\begin{array}{c}\mathrm{HOMO}^{a} \\
\text { Energy/eV }\end{array}$} & \multicolumn{8}{|c|}{$\Delta G^{\circ} / \mathrm{kJ} \mathrm{mol}^{-1}$} \\
\hline & & & PT1 & PT2 & PT3 & PT4 & ET1 & ET2 & ET3 & $\operatorname{Total}^{b}$ \\
\hline $\mathrm{CN}$ & 7.95 & -5.11 & 10.09 & 289.36 & -379.94 & -62.34 & 465.46 & 75.43 & -276.27 & 23.18 \\
\hline $\mathrm{Br}$ & 9.34 & -4.71 & 34.03 & 313.30 & -352.61 & -38.40 & 421.19 & 34.54 & -317.16 & 30.17 \\
\hline $\mathrm{H}$ & 9.98 & -4.60 & 45.25 & 324.52 & -355.97 & -27.18 & 425.28 & 24.05 & -327.65 & 42.12 \\
\hline $\mathrm{C}\left(\mathrm{CH}_{3}\right)_{3}$ & - & -4.44 & 50.27 & 329.53 & -341.07 & -22.16 & 401.40 & 10.06 & -341.64 & 38.16 \\
\hline $\mathrm{OH}$ & 9.96 & -4.28 & 52.58 & 331.85 & -331.47 & -19.85 & 377.24 & -6.81 & -358.51 & 25.92 \\
\hline $\mathrm{CH}_{3} \mathrm{O}$ & 10.20 & -4.27 & 53.13 & 332.40 & -322.67 & -19.30 & 366.12 & -9.68 & -361.38 & 24.15 \\
\hline $\mathrm{NH}_{2}$ & 10.30 & -4.09 & 56.11 & 335.38 & -298.08 & -16.31 & 315.13 & -39.07 & -390.77 & 0.72 \\
\hline $\mathrm{N}\left(\mathrm{CH}_{3}\right)_{2}$ & $-^{c}$ & -3.81 & 65.13 & 344.40 & -281.43 & -7.30 & 293.90 & -52.66 & -404.36 & 5.17 \\
\hline
\end{tabular}

a) $\mathrm{HOMO}$ energy of $\mathrm{PO}^{-}$.

b) $\triangle G^{\circ}$ values correspond to the $\mathrm{PCET}$ reaction, $\mathrm{O}_{2}{ }^{--}+2 \mathrm{POH} \rightarrow \mathrm{H}_{2} \mathrm{O}_{2}+\mathrm{PO}^{\circ}+\mathrm{PO}^{-}$.

c) This $p K_{a}$ value is not available in the literature but is estimated from the substituent constants to be greater than 10.5 .

A PCET reaction after the initial proton transfer from 4-aminophenol to $\mathrm{O}_{2}{ }^{--}$is important in efficient $\mathrm{O}_{2}{ }^{--}$scavenging. The PCET reaction involving the transfer of one electron and one proton from 4-aminophenolate anion to $\mathrm{HO}_{2}{ }^{\circ}$ can be described in terms of the four diabatic electronic states depicted in Fig. 4. The proton and electron are transferred in one kinetic step that corresponds to the diagonal of the lower rectangle in Fig. 4, labeled concerted PCET. This facilitates the kinetics of the concerted PCET mechanism. The PCET model of 4-aminophenol is shown in Fig. 6. Concerted PCET occurs in the hydrogen-bonded complex between 4-aminophenolate anions and $\mathrm{HO}_{2}{ }^{\circ}$ (Fig. 6). The proton transfer occurs along the $\mathrm{N}-\mathrm{H}^{\cdots} \mathrm{O}$ hydrogen bond from a lone pair $\sigma$-type orbital on the nitrogen atom of the 4-aminophenolate ion that is nominally in the plane of the molecular framework. This transfer is coupled to the electron transfer that occurs from the $\pi$-type lone pair of the oxygen atom of 4-aminophenolate ion to the singly occupied molecular orbital of $\mathrm{HO}_{2}{ }^{\circ}$. Note that the proton and electron are transferred in one kinetic step in the concerted PCET mechanism [45-49]. 


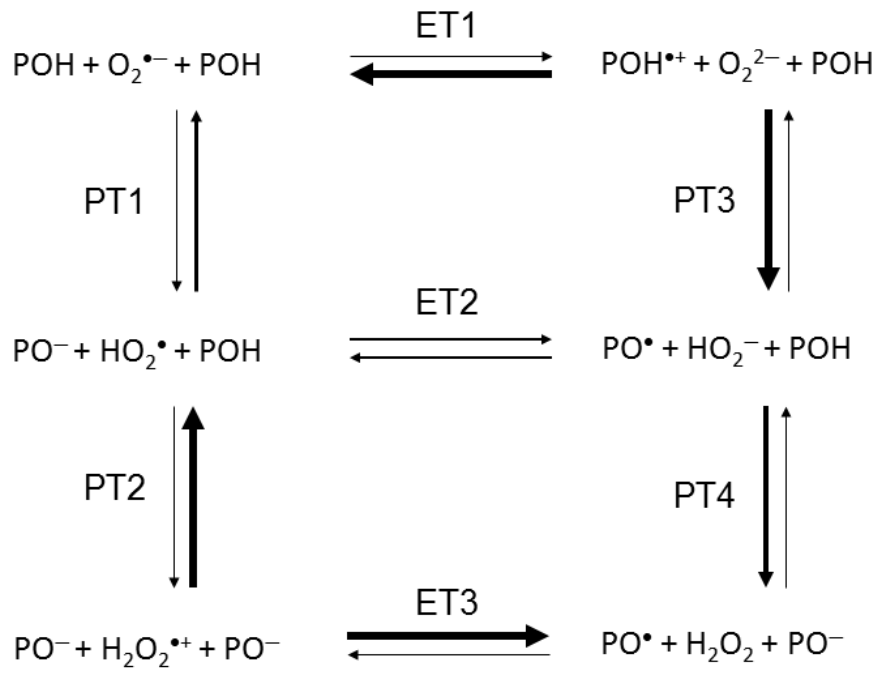

Fig.4. Six diabetic electronic states for the PCET reaction between $\mathrm{O}_{2}{ }^{--}$and $\mathrm{POH}$ involving two protons and one electron, based on the model shown in Fig. 1.

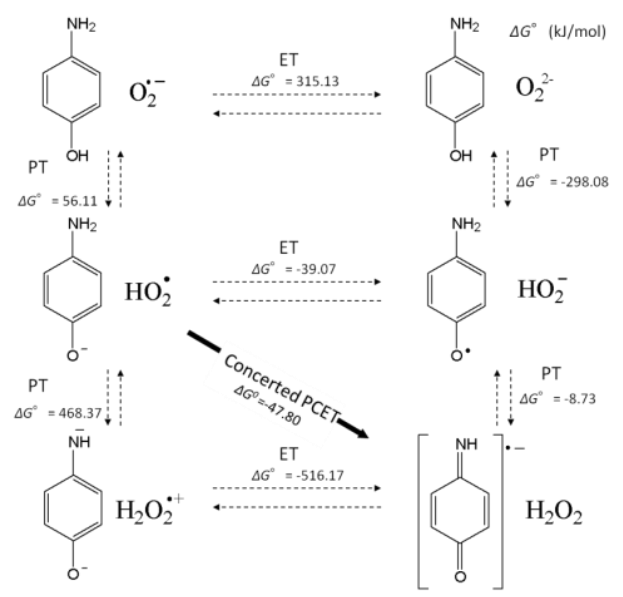

Fig5. Six diabetic electronic states and the $\triangle G^{\circ}$ values for the PCET reactions between $\mathrm{O}_{2}{ }^{--}$and 4-aminophenol (upper) and between $\mathrm{HO}_{2}{ }^{\circ}$ and 4-aminophenolate ion (lower) in DMF. The $\triangle G^{\circ}$ values $\left(\mathrm{kJ} \mathrm{mol}^{-1}\right)$ were calculated using the B3LYP/PCM/6-31+G(d,p) method.

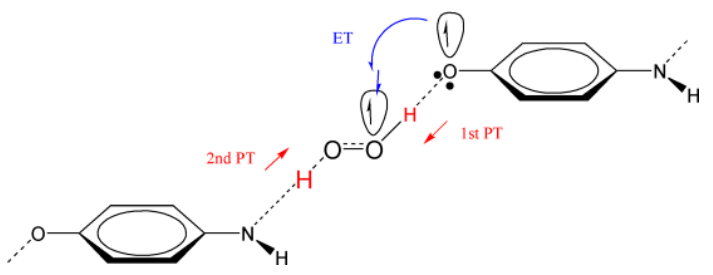

Fig.6. Plausible model for the PCET reaction of $\mathrm{O}_{2}{ }^{--}$scavenging by 4-aminophenol. The electron transfer occurs concertedly with the second proton transfer after the first proton transfer. See the text for details.

\section{Conclusions}

It has been demonstrated that a proton-transfer pathway is the major mechanism for the reaction between $\mathrm{O}_{2}{ }^{-}$and $\mathrm{POHs}$ except for 4-aminophenol and that the reaction is not influenced by the electronic substituent effect. In addition, 4-aminophenol shows a strong $\mathrm{O}_{2}{ }^{--}$scavenging effect despite its single hydroxyl group. It is suggested that structural properties of 4-aminophenol characterized by the $\pi$ electronic redox system involving two protons and two electrons are important in the $\mathrm{O}_{2}{ }^{--}$-scavenging PCET reaction. The concerted PCET reaction of the redox system of 4-aminophenol is believed to be similar to the quinone-hydroquinone electron transfer system involving an intermediate 
radical anion in the PCET process. The proposed concerted PCET reaction can be ascribed to the structural properties of the hydroxyl and amino groups in 4-aminophenol and the two hydroxyl groups in hydroquinone, as well as the stability of the intermediate radical anion in the 4-aminophenol redox system.

\section{ACKNOWLEDGEMENTS}

This work was supported by Grant-in-Aid for Scientific Research(C) Grant Number 25460039 from Japan Society for the Promotion of Science (JSPS). The authors would like to thank Mr. Yuki Mori for his experimental assistance.

\section{REFERENCES}

[1] Williams R. J., Spencer J. P. E., Rice-Evans C., Flavonoids: antioxidants or signaling molecules, Free Radical Bio. Med. 36, 838 (2004).

[2] Rice-Evans C. A., Miller N. J., Paganga G., Structure-antioxidant activity relationships of flavonoids and phenolic acids, Free Radical Biol. Med. 20, 933 (1996).

[3] Leopoldini M., Marino T., Russo N., Toscano M., Density functional computations of the energetic and spectroscopic parameters of quercetin and its radicals in the gas phase and in solvent, Theor. Chem. Acc. 111, 210 (2004).

[4] Cotelle N., Hapiot P., Pinson J., Rolando C., Vézin H., Polyphenols deriving from chalcones: Investigations of redox activities, J. Phys. Chem. B 109, 23720 (2005).

[5] Kozlowski D., Trouillas P., Calliste C., Marsal P., Lazzaroni R., Duroux J. -L., Density functional theory study of the conformational, electronic, and antioxidant properties of natural chalcones, $\mathrm{J}$. Phys. Chem. A 111, 1138 (2007).

[6] Dhaouadi Z., Nsangou M., Garrab N., Anouar E. H., Marakchi K., Lahmar S., DFT study of the reaction of quercetin with ${ }^{\circ} \mathrm{O}_{2}{ }^{-}$and ${ }^{\circ} \mathrm{OH}$ radicals, J. Mol. Struct. (Theochem) 904, 35 (2009).

[7] Nsangou M., Dhaouadi Z., Jaidane N., Lakhdar Z. B., DFT study of the structure of hydroxybenzoic acids and their reactions with $\mathrm{OH}$ and $\mathrm{O}_{2}^{-}$radicals, J. Mol. Struct. (Theochem) 850,135 (2008).

[8] Nsangou M., Fifen J. J., Dhaouadi Z., Lahmar S., Hydrogen atom transfer in the reaction of hydroxycinnamic acids with $\mathrm{OH}$ and $\mathrm{HO}_{2}$ radicals: DFT study, J. Mol. Struct. (Theochem) 862, 53 (2008).

[9] Fiorucci S., Golebiowski J., Cabrol-Bass D., Antonczak S., DFT study of quercetin activated forms involved in antiradical, antioxidant, and prooxidant biological processes, J. Agric. Food Chem. 55, 903 (2007).

[10] Wright J. S., Johnson E. R., DiLabio G. A., Predicting the activity of phenolic antioxidants: Theoretical method, analysis of substituent Effects, and application to major families of antioxidants, J. Am. Chem. Soc. 123(6), 1173 (2001).

[11] Russo N., Toscano M., Uccella N., Semiempirical molecular modeling into quercetin reactive site: structural, conformational, and electronic features, J. Agric. Food Chem. 48, 3232 (2000).

[12] Leopoldini M., Pitarch I. P., Russo N., Toscano M., Structure, conformation, and electronic properties of apigenin, luteolin, and taxifolin antioxidants. A first principle theoretical study, J. Phys. Chem. A 108, 92 (2004).

[13] Meo F. D., Lemaur V., Cornil J., Lazzaroni R., Duroux J.-L., Olivier Y., Trouillas P., Free radical scavenging by natural polyphenols: Atom versus electron transfer, J. Phys. Chem. A 117, 2082 (2013).

[14] Priyadarsini K. I., Maity D. K., Naik G. H., Kumar M. S., Unnikrishnan M. K., Satav J. G., Mohan $\mathrm{H}$., Role of phenolic $\mathrm{O}-\mathrm{H}$ and methylene hydrogen on the free radical reactions and antioxidant activity of curcumin, Free Radical Biol. Med. 35, 475 (2003). 
[15] Kong L., Wang L. -F., Zhang H. -Y., Theoretical elucidation on mechanism and reactivity of bisphenol A derivatives as inhibitors and radical scavengers in methacrylate polymerization, J. Mol. Struct. (Theochem) 716, 27 (2005).

[16] Foti M. C., Daquino C., Geraci C., Electron-transfer reaction of cinnamic acids and their methyl esters with the DPPH(*) radical in alcoholic solutions, J. Org. Chem. 69, 2309 (2004).

[17] Fridovich I., Superoxide anion radical $\left(\mathrm{O}_{2}{ }^{-{ }^{-}}\right)$, superoxide dismutases, and related matters, J. Biol. Chem. 272, 18515 (1997).

[18] Halliwell B., Oxygen and nitrogen are pro-carcinogens. Damage to DNA by reactive oxygen, chlorine and nitrogen species: measurement, mechanism and the effects of nutrition, Mutat. Res. 443, 37 (1999).

[19] Lu Y., Foo L. Y., Antioxidant and radical scavenging activities of polyphenols from apple pomace, Food Chem. 68, 81 (2000).

[20] Lu Y., Foo L. Y., Antioxidant activities of polyphenol from sage (Salvia officinalis), Food Chem. 75, 197 (2001).

[21] Litwinienko G., Ingold K. U., Solvent Effects on the Rates and Mechanisms of Reaction of Phenols with Free Radicals, Acc. Chem. Res. 40, 222 (2007).

[22] Marković M. J. D., Milenković D., Amić D., Mojović M., Paštia I., Markovićbd Z. S., The preferred radical scavenging mechanisms of fisetin and baicalein towards oxygen-centred radicals in polar protic and polar aprotic solvents, RSC Adv. 4, 32228 (2014).

[23] Bourvellec C. L., Hauchard D., Darchen A., J. -L. Burgot, M. -L. Abasq, Validation of a new method using the reactivity of electrogenerated superoxide radical in the antioxidant capacity determination of flavonoids, Talanta 75, 1098 (2008).

[24] René A., Abasq M. -L., Hauchard D., Hapiot P., How do phenolic compounds react toward superoxide ion? A simple electrochemical method for evaluating antioxidant capacity, Anal. Chem. 82,8703 (2010).

[25] Nakayama T., Uno B., Quinone-hydroquinone $\pi$-conjugated redox reaction involving proton-coupled electron transfer plays an important role in scavenging superoxide by polyphenolic antioxidants, Chem. Lett. 39, 162 (2010).

[26] Nakayama T., Uno B., Importance of proton-coupled electron transfer from natural phenolic compounds in superoxide scavenging, Chem. Pharm. Bull. 63, 967 (2015).

[27] Chun O. K., Kim D. -O., Lee C. Y., Superoxide radical scavenging activity of the major polyphenols in fresh plums, J. Agric. Food Chem. 51, 8067 (2003).

[28] [28] Fridovich I., Superoxide anion radical $\left(\mathrm{O}_{2}{ }^{-}\right)$, superoxide dismutases, and related matters, J. Biol. Chem. 272, 18515 (1997).

[29] Halliwell B., Oxygen and nitrogen are pro-carcinogens. Damage to DNA by reactive oxygen, chlorine and nitrogen species: measurement, mechanism and the effects of nutrition, Mutat. Res. 443, 37 (1999).

[30] Birnboim H. C., DNA strand breaks in human leukocytes induced by superoxide anion, hydrogen peroxide and tumor promoters are repaired slowly compared to breaks induced by ionizing radiation, Carcinogenesis 7, 1511 (1986).

[31] Birnboim H. C., Kanabus-Kaminska M., The production of DNA strand breaks in human leukocytes by superoxide anion may involve a metabolic process, Proc. Natl. Acad. Sci. U.S.A. 82, 6820 (1985).

[32] Bagley A. C., Krall K., Lynch R. E., Superoxide mediates the toxicity of paraquat for Chinese hamster ovary cells, Proc. Natl. Acad. Sci. U.S.A. 83, 3189 (1986).

[33] Fridovich I., Biological effects of the superoxide radical, Arch. Biochem. Biophys. 247, 1 (1986).

[34] Nanni Jr. E. J., Stallings M. D., Sawyer D. T., Does superoxide ion oxidize catechol, O-tocopherol, and ascorbic acid by direct electron transfer? J. Am. Chem. Soc. 102, 4481 (1980). 
[35] Sawyer D. T., Chiericato Jr. G., Angelis C. T., Nanni Jr. E. J., Tsuchiya T., Effects of media and electrode materials on the electrochemical reduction of dioxygen, Anal. Chem. 54, 1720 (1982).

[36] Wilshire J., Sawyer D. T., Redox chemistry of dioxygen species, Acc. Chem. Res. 12, 105 (1979).

[37] Sawyer D. T., Valentine J. S., How super is superoxide? Acc. Chem. Res. 14393 (1981).

[38] Andrieux C. P., Hapiot P., Saveant J. M., Mechanism of superoxide ion disproportionation in aprotic solvents, J. Am. Chem. Soc. 109, 3768 (1987).

[39] Singh P. S., Evans D. H., Study of the electrochemical reduction of dioxygen in acetonitrile in the presence of weak acids, J. Phys. Chem. B. 110, 637 (2006).

[40] Gilman H., Avakian S., Benkeser R. A., Broadbent H. S., Clark R. M., Karmas G., Marshall F. J., Massie S. M., Shirley D. A., Woods L. A., The synthesis of $\mathrm{N}$-methyl-3-isopropyl-4-dimethylaminophenyl carbamate and some related derivatives, J. Org. Chem. 19, 1067 (1954).

[41] Kubota T., Kano K., Uno B., Konse T., Energetics of the sequential electroreduction and electrooxidation steps of benzenoid hydrocarbons, Bull. Chem. Soc. Jpn. 60, 3865 (1987).

[42] Kano K., Mori K., Konse T., Uno B., Kubata T., In-situ electron spin resonance and voltammetric studies using an internal-flow-type electrolysis cell, Anal. Sci. 5, 651 (1989).

[43] Frisch M. J., Trucks G. W., Schlegel H. B., Scuseria G. E., Robb M. A., Cheeseman J. R., Scalmani G., Barone V., Mennucci B., Petersson G. A., Nakatsuji H., Caricato M., Li X., Hratchian H. P., Izmaylov A. F., Bloino J., Zheng G., Sonnenberg J. L., Hada M., Ehara M., Toyota K., Fukuda R., Hasegawa J., Ishida M., Nakajima T., Honda Y., Kitao O., Nakai H., Vreven T., Montgomery Jr., J. A., Peralta J. E., Ogliaro F., Bearpark M., Heyd J. J., Brothers E., Kudin K. N., Staroverov V. N., Keith T., Kobayashi R., Normand J., Raghavachari K., Rendell A., Burant J. C., Iyengar S. S., Tomasi J., Cossi M., Rega N., Millam J. M., Klene M., Knox J. E. Cross J. B., Bakken V., Adamo C., Jaramillo J., Gomperts R., Stratmann R., E., Yazyev O., Austin A. J., Cammi R., Pomelli C., Ochterski J. W., Martin R. L., Morokuma K., Zakrzewski V. G., Voth G. A., Salvador P., Dannenberg J. J., Dapprich S., Daniels A. D., Farkas O., Foresman J. B., Ortiz J. V., Cioslowski J., Fox D. J., Gaussian 09, Revision B.01, Gaussian, Inc., Wallingford CT, 2010.

[44] Beiginejad H., Nematollahi D., Varmaghani F., Electrochemical oxidation of some aminophenols in various pHs, J. Electrochem. Soc. 160(1), H41 (2013).

[45] Huynh M. H. V., Meyer T. J., Proton-coupled electron transfer, Chem. Rev. 107, 5004 (2007).

[46] Weinberg D. R., Gagliardi C. J., Hull J. F., Murphy C. F., Kent C. A., Westlake B. C., Paul A., Ess D. H., McCafferty D. G., Meyer T. J., Proton-coupled electron transfer, Chem. Rev. 112, 4016 (2012).

[47] Costentin C., Electrochemical approach to the mechanistic study of proton-coupled electron transfer, Chem. Rev. 108, 2145 (2008).

[48] Hammes-Schiffer S., Proton-coupled electron transfer: Moving together and charging forward, J. Am. Chem. Soc. 137, 8860 (2015).

[49] Mayer J. M., Rhile I. J., Thermodynamics and kinetics of proton-coupled electron transfer: stepwise vs. concerted pathways, Biochim. Biophys. Acta 1655, 51 (2004). 